\title{
RESEARCH
}

\section{A Hospital Based Study of Profile of Anterior Uveitis in Tertiary Care Hospital of Nepal}

\author{
Joshi S L ${ }^{* 1}$, Kaiti $\mathbf{R}^{2}$ \\ ${ }^{1}$ Department of Ophthalmology, R. M. Kedia Eye Hospital, Birgunj, Nepal. \\ ${ }^{2}$ Department of Ophthalmology, Nepal Eye Hospital, Kathmandu, Nepal.
}

Date of Submission : March 16, 2019

Received in Revised Form: March 26, 2019

Date of Acceptance: April 10, 2019

Date of Publishing: July 30, 2019

\begin{abstract}
Background:

Anterior uveitis is the most common form of intraocular inflammation with a varying degree of incidence in the general population. Inspite of advanced investigational and research facilities anterior uveitis still remains a significant cause of visual impairment in the developing and also in the developed countries. The aim of this study was to determine the profile of anterior uveitis and outcome following the treatment presenting to Ophthalmology Department of Dhulikhel Hospital.
\end{abstract}

\section{Methods:}

This was a prospective hospital-based study done at the Department of Ophthalmology in Dhulikhel Hospital, Kathmandu University Hospital for a period of one year. All the patients with anterior uveitis aged 5 years and above attending the outpatients department were included into the study. A detailed epidemio-logical data was collected and complete ocular examination was performed by the Ophthalmo-logist.

\section{Results:}

A total of 7950 patients were seen in the Ophthalmology outpatient department during a one year period, out of which 43 patients were cases of anterior uveitis. The overall prevalence of anterior uveitis was $5.4 \%$. Among the screened patients, there were 31 males $(72.1 \%)$ and 12 females $(27.9 \%)$. The largest proportion of respondents contributed was 20-29 years old that is 13 .

\section{Conclusion:}

Anterior uveitis is a common ocular problem. Often it is misdiagnosed, as the presenting symptoms are minimal. This can lead to permanent visual impairment. The early diagnosis and appropriate treatment can save the vision without significant sequelae and good visual outcome.

Keywords: Anterior Uveitis, Epidemiology, Nepal

*Corresponding Author: Dr. Leesha Shrestha Joshi, Department of Ophthalmology, R.M.Kedia Eye Hospital, Birgunj,Nepal.

Email:shreslisa@yahoo.com.

\section{INTRODUCTION}

Uveitis is one of the significant form of potentially blinding inflammatory ocular disease. It is the major cause of severe visual impairment. Globally, anterior uveitis is the most common form of intraocular inflammation with a varying degree of incidence in the general population. Anatomically anterior uveitis comprises inflammation of the iris alone also called as iritis, anterior part of ciliary body called as anterior cyclitis or both structures known as iridocyclitis. 
In early treatment it is generally less sight threatening and less serious than posterior segment inflammation. ${ }^{2}$ This condition may present as a benign condition but often can lead to severe morbidity if not treated on time appropriately. ${ }^{3}$ Majority (12-33\%) of patients with anterior uveitis don't have identifiable etiology to their inflammation and such uveitis is considered to be idiopathic. ${ }^{4-7}$ HLA B27 is the most common identifiable association accounting for $18-32 \%$ of all acute in Western countries. ${ }^{8}$ HLA B27 can occur with ocular involvement or as part of the seronegative spondyloarthropathies, such as ankylosing spondylitis, reactive arthritis, psoriatic arthritis and inflammatory bowel disease. ${ }^{9}$ The prevalence of HLA B27 in patients with acute anterior uveitis is around $50 \% .^{10}$ Anterior uveitis may be the first symptom of a seronegative spondyloarthropathy preceding the onset of other clinical manifestations. ${ }^{11}$

Uveitis includes a large group of diverse inflammatory diseases, the frequencies of which vary greatly by geographic location around the globe. In US, it accounts for $10-15 \%$ of all cases of total blindness. ${ }^{12}$ Legal blindness developed at least in one eye is $22 \%$ of all uveitis patients and about $23 \%$ of all with required intraocular surgery. ${ }^{13}$ Anterior uveits most commonly encountered (27-58\%) entity followed by posterior uveitis (29-38\%), intermediate uveitis $(2-7 \%)$ and panuveitis (12-18\%). ${ }^{4-7}$ All form of uveits i.e anterior, intermediate, posterior and panuveitis contribute to more than $10 \%$ of visual impairment in the western countries. The common causes of uveitis change with age and children aged less than 10 years have a very different range of diagnoses and complications compared to the adult uveitis population. ${ }^{14}$

Anterior uveitis is a common ocular problem. Often it is misdiagnosed, as the presenting symptoms are minimal. This can lead to permanent visual impairment. Therefore proper management is necessary. Visual outcome following treatment of anterior uveitis has not been studied in Nepalese population and hence the study to make a proper guideline for the treatment of anterior uveitis at Dhulikhel Hospital with the objective to find out the outcome following treatment guideline along the demographic profile, clinical presentation, systemic association and complications of anterior uveitis. $^{15}$

\section{MATERIALS AND METHODS}

This is a prospective hospital based study carried out in the Department of Ophthalmology in Dhulikhel Hospital, Kathmandu University Hospital from Feb 2016- Feb 2017, for a period of one year after obtaining ethical clearance from Institutional Review Committee from IRC, KUSMS. All the patients above 5 years of age, diagnosed as anterior uveitis attending the outpatient department, were explained about the study. Those who could understand and give consent were enrolled into the study. Written informed consent was obtained from all the subjects before participation. Cases fulfilling the inclusion and exclusion criteria were examined in detail. All patients above 5 years of age, diagnosed as non infectious cases of anterior uveitis were included. Patients having other ocular diseases, causing visual impairment, e.g.corneal opacities, cataracts, patients on long term treatment for systemic diseases (steroids, immunosuppressive or anticancer drugs), recurrent uveitis and patients not cooperating for slit lamp examination were excluded. All enrolled cases of anterior uveitis underwent a complete ophthalmological examination by the Ophthalmologist.

All the information about age, gender, race details of ocular examination, investigations, diagnosis and systemic disease association was recorded. Anterior uveitis was diagnosed and systemic association was made by clinical history, ophthalmological examination, general physical examination, laboratory and ancillary tests. Distance, near and best corrected visual acuity were taken using internally illuminated Snellen's multiple optotype for literate patients and E chart for the illiterates. Refraction of all patients were done by using a retinoscope .

The diagnosis of anterior segment was made by using a slit-lamp biomicroscope (Haag-Streit model BQ-900, Bern, Switzerland) by the same Ophthalmologist. Anterior chamber inflammation was graded by the presence of cells and flares. Anterior chamber cells and flares grading given by The Standardization of Uveitis Nomenclature (SUN) Working Group was followed and the grading is given below:

The (SUN) Working Group Grading Scheme for Anterior Chamber Cells. 
Grade Cells in Field

- $0<1$

- $0.5+1-5$

- $1+6-15$

- $2+16-25$

- $3+26-50$

- $4+>50$

The (SUN) Working Group Grading Scheme for Anterior Chamber Flare.

Grade Description

- 0 None

- $1+$ Faint

- 2+Moderate (iris and lens details clear)

- 3+ Marked (iris and lens details hazy)

- 4+ Intense (fibrin or plastic aqueous)

Aqueous flare and cells measured by counting within the field visible with a slit lamp

keeping the beam $2 \mathrm{~mm}$ height, $1 \mathrm{~mm}$ width at maximum intensity with high magnification.

All the participants underwent dilated posterior segment evaluation and examination of the fundus by 90 diopter Volk lens. General physical examination was performed. A tailored laboratory investigation was carried out. Investigation included TC, DC, ESR, Hb, CXR- PA view, Mantoux test,Urine routine, Stool routine, Rheumatoid factor,VDRL, X-ray sacroiliac joint.

IOP was taken by Goldmann applanation tonometer. Other special investigations were considered whenever necessary. The final diagnosis was made based on history, clinical features, laboratory investigations and systemic evaluation. All the patients were treated with topical steroids and topical cycloplegic mydriatics. Steroids frequency was titrated according to the severity of uveitis. The management protocol is given below.

\section{MANAGEMENT PROTOCOL (working protocol)}

Working Group Features Treatment protocol

$\begin{array}{ll}\begin{array}{l}\text { I Cases with } \\ \text { Cells grade I } \\ \text { Flare grade I }\end{array} & \begin{array}{l}\text { Prednisolone acetate } 1 \% 4 \text { times a day. } \\ \text { Atropine sulphate } 3 \text { times a day. }\end{array} \\ \begin{array}{l}\text { Cells grade II -III } \\ \text { Flare grade II -III }\end{array} & \begin{array}{l}\text { Prednisolone acetate } 1 \% 2 \text { hourly. } \\ \text { Atropine sulphate } 3 \text { times a day. }\end{array} \\ \text { III Cases with } & \text { Prednisolone acetate } 1 \% \text { half hourly or } \\ \text { Cells grade IV } & \begin{array}{l}\text { hourly.Atropine sulphate } 3 \text { times a day } \\ \text { with or without mydricain. Injection }\end{array} \\ \text { Flare grade IV } & \text { dexona subconjuctival. } \\ \text { IV Bilateral cases group III } & \text { Oral prednisolone } 1 \mathrm{mg} / \mathrm{kg} \text { body weight } \\ \text { or Resistant to topical } & \text { with } \\ \text { corticosteroids } & \text { treatment of group }\end{array}$

Patients was followed up 3 rd day, $7^{\text {th }}$ day after 1 st visit, weeks after 2 nd visit Patient's demographic profile and clinical examination results have been entered in the specially designed Porforma and then in the computer. Statistical analysis was performed using SPSS with significance attributed to $\mathrm{P}<0.05$.

\section{RESULTS}

A total number of 43 patients were screened as the case of anterior uveitis. Among the screened patients, there were 31 males $(72.1 \%)$ and 12 females $(27.9 \%)$. The largest proportion of respondents contributed was 20-29 years old i.e 13.

Table 1: Distribution of patients according to age group

\begin{tabular}{|c|c|c|c|c|c|c|}
\hline \multirow{2}{*}{ Age group } & \multicolumn{4}{|c|}{ Sex } & \multirow{2}{*}{\multicolumn{2}{|c|}{ Total }} \\
\hline & \multicolumn{2}{|c|}{ Male } & \multicolumn{2}{|c|}{ Female } & & \\
\hline$<19$ years & 4 & $57.1 \%$ & 3 & $42.9 \%$ & 7 & $100.0 \%$ \\
\hline $20-29$ years & 9 & $69.2 \%$ & 4 & $30.8 \%$ & 13 & $100.0 \%$ \\
\hline $30-39$ years & 7 & $70.0 \%$ & 3 & $30.0 \%$ & 10 & $100.0 \%$ \\
\hline $40-49$ years & 3 & $60.0 \%$ & 2 & $40.0 \%$ & 5 & $100.0 \%$ \\
\hline $50-59$ years & 4 & $100.0 \%$ & 0 & $.0 \%$ & 4 & $100.0 \%$ \\
\hline$>60$ years & 4 & $100.0 \%$ & 0 & $.0 \%$ & 4 & $100.0 \%$ \\
\hline Total & 31 & $72.1 \%$ & 12 & $27.9 \%$ & 43 & $100.0 \%$ \\
\hline
\end{tabular}

Anterior uveitis was seen more in male i.e $31(72.1 \%)$ and female is $12(27.9 \%)$. The most common age group was 20-29 years where $(69.2 \%)$ were male and $4(30.8 \%)$ were female.

Table 2: Distribution of patient by district

\begin{tabular}{|l|c|c|c|c|}
\hline \multicolumn{1}{|c|}{ Address } & Frequency & Percent & Valid Percent & $\begin{array}{c}\text { Cumulative } \\
\text { Percent }\end{array}$ \\
\hline Sindhupalchowk & 6 & 14.0 & 14.0 & 14.0 \\
\hline Kavre & 9 & 20.9 & 20.9 & 34.9 \\
\hline $\begin{array}{l}\text { Dhulikhel, } \\
\text { Banepa, Panauti }\end{array}$ & 13 & 30.2 & 30.2 & 65.1 \\
\hline Bhaktapur & 6 & 14.0 & 14.0 & 79.1 \\
\hline $\begin{array}{l}\text { Sindhuli, } \\
\text { Ramechhap }\end{array}$ & 6 & 14.0 & 14.0 & 93.0 \\
\hline Kathmandu & 3 & 7.0 & 7.0 & 100.0 \\
\hline Total & $\mathbf{4 3}$ & $\mathbf{1 0 0 . 0}$ & $\mathbf{1 0 0 . 0}$ & \\
\hline
\end{tabular}

Anterior uveitis was found to be in highest proportion in residents of Dhulikhel, Banepa, Panauti $(30.2 \%, n=13)$ in this study population. This was followed by residents of kavre. 
Table 3: Most common presenting symptoms

\begin{tabular}{|l|l|l|l|}
\hline \multicolumn{1}{|c|}{ Symptoms } & \multicolumn{1}{c|}{ Present } & \multicolumn{1}{c|}{ Absents } & \multicolumn{1}{c|}{ Total } \\
\hline Red eye & $41(95.3 \%)$ & $2(4.7 \%)$ & $43(100 \%)$ \\
\hline Blurring of vision & $35(81.4 \%)$ & $8(18.6 \%)$ & $43(100 \%)$ \\
\hline Pain & $27(62.8 \%)$ & $16(37.2 \%)$ & $43(100 \%)$ \\
\hline Photophobia & $21(48.8 \%)$ & $22(51.2 \%)$ & $43(100 \%)$ \\
\hline
\end{tabular}

In this study the right eye 27(62.8) was involved more than the left eye 16(37.2). The most common symptoms presented was red eye 41 $(95.3 \%)$ followed by blurring of vision $35(81.4 \%)$, pain $27(62.8 \%)$ and photophobia $21(48.8 \%)$.

Table 4: Pre and post treatment Visual Acuity

\begin{tabular}{|l|l|l|l|l|}
\hline \multirow{2}{*}{ VA } & VA first visit & VA first follow up & $\begin{array}{c}\text { VA second follow } \\
\text { up }\end{array}$ & VA third follow up \\
\cline { 2 - 5 } & $\begin{array}{c}\text { Frequency } \\
(\%)\end{array}$ & Frequency $(\%)$ & Frequeney $(\%)$ & \multicolumn{1}{|c|}{ Frequency (\%) } \\
\hline $6 / 6$ to $6 / 12$ & $29(67.4)$ & $28(65.1)$ & $33(76.7)$ & $38(88.4)$ \\
\hline $6 / 18$ to $6 / 36$ & $7(16.3)$ & $10(23.3)$ & $8(18.6)$ & $4(9.3)$ \\
\hline$<6 / 60$ & $7(16.3)$ & $5(11.6)$ & $2(4.7)$ & $1(2.3$ \\
\hline Total & $\mathbf{4 3 ( 1 0 0 . 0 )}$ & $\mathbf{4 3 ( 1 0 0 . 0 )}$ & $\mathbf{4 3 ( 1 0 0 . 0 )}$ & $\mathbf{4 3 ( 1 0 0 . 0 )}$ \\
\hline
\end{tabular}

The above table shows that at the time of presentation the visual acuity was different ranging from $6 / 6$ to less than 6/60. But after treatment the vision was improved in the third follow to the range of 6/6-6/12.

Table 5: Distribution of Anterior Chamber cells pre and post treatment

\begin{tabular}{|l|l|l|l|l|}
\hline \multirow{2}{*}{ AC cells } & \begin{tabular}{c} 
VA first visit \\
\cline { 2 - 5 }
\end{tabular} & $\begin{array}{c}\text { VA first follow } \\
\text { up }\end{array}$ & $\begin{array}{c}\text { VA second follow } \\
\text { up }\end{array}$ & VA third follow up \\
\hline Grade 0 & & Frequency (\%) & \multicolumn{1}{|c|}{ Frequency (\%) } & \multicolumn{1}{|c|}{ Frequency (\%) } \\
\hline Grade 1 & $9(20.9)$ & $15(34.9)$ & $20(46.5)$ & $36(83.7)$ \\
\hline Grade 2 & $12(27.9)$ & $13(30.2)$ & $5(11.6)$ & $6(14.0)$ \\
\hline Grade 3 & $17(39.5)$ & $9(20.9)$ & & \\
\hline Grade 4 & $5(11.6)$ & & & $1(2.3)$ \\
\hline Total & $\mathbf{4 3 ( 1 0 0 . 0 )}$ & $\mathbf{4 3 ( 1 0 0 . 0 )}$ & $\mathbf{4 3 ( 1 0 0 . 0 )}$ & $\mathbf{4 3 ( 1 0 0 . 0 )}$ \\
\hline
\end{tabular}

In the above table shows the sign of inflammation that is cells at the time of presentation and improvement of inflammation after treatment in the follow ups. At the time of presentation the most of the cases had the inflammation of grade 3 (n-17) followed by grade 2 (n-12). But after treatment the sign of inflammation decreased upto grade 0 i.e absence of inflammation. Only few cases had grade 1 inflammation and 1 case had grade 4 inflammation.

\section{DISCUSSION}

Anterior uveitis is the condition that involves inflammation of the uveal tract (iris, anterior part of ciliary body). The ophthalmologist's goal in treating these potentially blinding conditions is to eliminate the inflammatory reaction within the eye while minimizing the potential risks of therapy to the patient. This is best achieved once an accurate diagnosis has been obtained. Numerous methods of classifying uveitis have been used in the past, the classification scheme recommended by the International Uveitis Study Group and the Standardization of Uveitis Nomenclature (SUN) Working Group is based on anatomic location. In addition, descriptors of uveitis are used to further define the type of inflammation the patient exhibits. These include onset (sudden vs. insidious), duration (limitedless than 3 months duration, persistent- greater than 3 months duration) and course (acute, recurrent or chronic). Additional features such as laterality (unilateral vs. bilateral), granulomatous vs. nongranulomatous appearance may also be helpful in determining an etiology for a uveitis.

In 2010, Rupesh V Agrawal,defined anterior uveitis as the most commonest form of uveitis with varying incidences reported in worldwide literature. Shrestha J B et al also stated that anterior uveitis was the most common form of intraocular inflammation followed by posterior, pan and intermediate uveitis. ${ }^{16}$ Manandhar A also stated Anterior uveitis (590, 53\%) was most common, followed by panuveitis $(20 \%)$, intermediate uveitis $(14 \%)$, then posterior uvietis $(12.9 \%) .^{17}$ In contrast, in the study by Henderly et al posterior uveitis was most common form of uveitis $(38.4 \%)$ in the USA. ${ }^{5}$ Anterior uveitis can be very benign to present with but often can lead to severe morbidity if not treated appropriately. ${ }^{3}$

In this study anterior uveitis was seen more in male i.e $31(72.1 \%)$ and female is $12(27.9 \%)$. The most common age group was $20-29$ years where $9(69.2 \%)$ were male and $4(30.8 \%)$ were female.In this study males were affected more than females. which is similar to observations made by Rathinam et al. ${ }^{18,19}$ but in contrary Rodriguez A et al. reported female preponderance of the disease. This may be because men tend to seek medical attention more often than women, and socioeconomic habits may put male patients at a greater risk for development of anterior uveitis. ${ }^{4}$ Ebrahim M. et al also stated that average age and male to female ratio did not differ 
significantly between Middle Eastern and European studies. ${ }^{20}$

It was seen that the youngest patient was 16years and the oldest was 71 years old. Ralph D Levinson et al stated that uveitis may develop in patients of any age but most commonly in the fourth and fifth decade of life. He also stated there was no significant sexual differences, although, the maleto-female ratio of ankylosing spondylitis, which is a common cause of iritis, is $3: 1{ }^{21}$ Albert and Jakobies had stated that below the age of 16 years the incidence is relatively uncommon but then subsequently increases. The number of occurrence of uveitis in age group 15-40 was found to be $75 \%$ which is statistically significantly higher ( $\mathrm{p}$ value $=0.00061){ }^{2} \mathrm{He}$ also stated that rates of uveitis were higher in women than in men which was not similar to this study where male rates were higher than female $(43.8 \%)^{22}$

Anterior uveitis was found to be in highest proportion in residents of Dhulikhel, Banepa, Panauti $(30.2 \%, \mathrm{n}=13)$ in this study population. This was followed by residents of kavre. As no previous study of anterior uveitis has been done in Nepal, thus no comparision regarding proportion of residents could be made. But there was a study done in intermediate uveitis in which the study population of intermediate uveitis was found to be in highest proportion in residents of Dhading district.

Majority of patients in this study came with unilateral presentation which was comparable with that of Rathinam et al study. Bilateral involvement was absent. However there was no significant predilection for either the right or left eye.In this study the right eyes $(62.8 \%, \mathrm{n}=27)$ were affected more than the left eyes $(37.2 \%$, $\mathrm{n}=16$ ). But in other studies there were significantly no differences. The most presenting symptoms in this study were blurred vision and red eye which was followed by photophobia and pain. Albert and Jakobies had stated acute uveitis affecting the front of the eye normally presents with redness, pain, photophobia and a small reduction in visual acuity. In chronic anterior uveitis (CAU) the onset may be insidious with a white eye and gradual loss of vision. In many types of uveitis entities where it is only one eye that is usally affected such as Fuchs' heterochromic cyclitis (FHC), herpetic anterior uveitis and Posner- Schlossman syndrome. ${ }^{22}$ Ralph D Levinson mentioned the common symptoms are dull, aching eye pain occurs and may worsen when one touches the eye through the eyelid. $^{21}$

In this study the most common sign was keratic precipitates which was present in most of the patients followed by cells, flare and posterior synechiae. Most of the patients presented with cells grade $3(39.5 \%, \mathrm{n}=17)$ and cell grade 2 $(27.9 \%, n=12)$ followed by grade 1 and grade 4 . Following treatment the inflammation of anterior chamber decreased to grade 0 and grade 1 .

In this study there were four different group for treatment and among them most of the patients were treated with working group 2. Corticosteroids represent the primary initial therapeutic modality in patients who have noninfectious uveitis. These medications produce a broad suppression of the immune system and achieve their anti-inflammatory effect by a number of mechanisms. Corticosteroids are given either topically, by periocular injection, intravitreally, or systemically. Prednisolone acetate is generally regarded as the most effective topical corticosteroid for treating anterior uveitis.Quan Dong Nguyen et al defined that Corticosteroids (CS) are the only approved drug class for treatment of noninfectious uveitis by the U.S. Food and Drug Administration. ${ }^{23}$ Ralph D Levinson also mentioned that topical corticosteroids are the mainstays of therapy and should be used aggressively during the initial phases of therapy. ${ }^{24}$

Visual acuity was $6 / 12$ or worse in the majority of eyes at presentation. Following treatment most eyes regained visual acuity of $6 / 9$ or better. In few eyes with complicated macular edema or retinal detachment, visual acuity improved marginally.

In this study most of the patient had no complications, only 3 cases developed complications. One case developed retinal detachment, one macular edema and one case developed vasculitis. Uveitis Information Group stated most complications are blurring of vision, floaters, persistent pain and redness, cataracts, rise in intraocular pressure (IOP), synechiae. Sometimes due to the inflammation, the iris becomes 'sticky' and it sticks to the lens which sits close behind it. 
(posterior synechiae). This can distort the shape of the iris and sometimes can influence the IOP.Mayo foundation for Medical Education and Research mentioned that if left untreated, uveitis can cause abnormally high pressure inside the eye (glaucoma), damage to the optic nerve, clouding of the lens (cataract) or cornea, retinal problems, such as fluid within the retina or retinal detachment, vision loss. ${ }^{25}$

Jennifer E. studied topical corticosteroid use was associated with an increased risk of cataract formation independent of active uveitis or presence of posterior synechiae. However, chronic use of topical corticosteroids in doses of 3 drops daily seemed to be associated with a lower risk of cataract development relative to eyes receiving higher doses over follow-up in the setting of suppressed uveitis. ${ }^{26}$ Victor Menezo et al in 2005 defined that The visual prognosis for patients with chronic anterior uveitis is generally good. Posterior segment complications appear to be more likely to occur if there is an underlying associated disease. However, the presence of complications does not seem to affect the visual outcome in patients with chronic anterior uveitis. ${ }^{27}$ No patient required anti-metabolities or immunosuppressive.

The limitation of this study is small sample size and the duration of follow up is not adequate to evaluate the optimum outcome of treatment modality.

\section{CONCLUSION}

Anterior uveitis is a common ocular problem with minimal symptoms to permanent visual impairment. It is a long lasting problem with a high rate of recurrence. The early diagnosis and appropriate treatment can save the vision without significant sequelae and good visual outcome.

\section{ACKNOWLEDGMENT}

I would like to thank Mr. Seshananda Sanjel (MPH) for his assistance in statistical analysis.

\section{REFERENCES}

1. J H Chang, R Raju, TRM Henderson, PJ McCluskey. Incidence and pattern of acute anterior uveitis in Central Australia, Br J Ophthalmol. 2010,94,154-156

2. Jabs DA, Nussenblatt RB, Rosenbaum JT.
Standardization of uveitis nomenclature (SUN) for reporting clinical data. Results of the First International Workshop. Am J Ophthalmol. 2005

3. Rupesh V Agrawal, Somasheila Murthy, Virender Sangwan, and Jyotirmay Biswas. Current approach in diagnosis and management of anterior uveitis,Indian J Ophthal. 2010,58,11-19

4. Rodriguez A, Calonge M, Pedroza-Seres, Akova YA, Messmer EM, D'Amico DJ, Foster CS. Referral patterns of uveitis in a tertiary eye care center. Arch Ophthalmol.1996;114:593-99

5. Henderly DE, Genstler AJ, Smith RE, Rao NA. Changing patterns of uveitis. Am J Ophthalmol. 1987;103:131-36

6. Mercanti A, Parolini B, Bonora A, Lequaglie Q, Tomazzali. Epidemiology of endogenous uveitis in North -Eastern Italy. Analysis of 655 new cases. Acta Ophthalmol Scand. 2001;79:64-68

7. Biswas J, Narain S, Das D, Ganesh SK. Pattern of uveitis in a referral uveitis clinic in India. Int Ophthalomol. 1996-97; 20:223-28

8. Wakefield D, Montanaro A, McCluskey P.Acute anterior uveitis and HLA B27.Surv Ophthalmol 1991; 36:223-232

9. Albert and Jakoiec: Principles and practice of Ophthalmology; Second Edition;2008;1138-1139

10. Suhler EB, Martin TM, Rosenbaum JT:HLAB27 associated uveitis: overview and current perspectives. Curr Opin Ophthalmol. 2003;14:378-383

11. Monnet D, Breban M, Hudry C, et al: Ophthalmic findings and frequency of extraocular manifestations in patients with HLA B27 uveitis: a study of 175 cases. Ophthalmology. 2004; 111:802809

12. Nussenblatt RB. The natural history of uveitis. Int Ophthalmol. 1990;14:303-8

13. Vadot E, Barth E, Billet P. Epidemiology of uveitis-preliminary results of a prospective study in Savoy. In: Saari KM, ed. Uveitis update. Amsterdam: Elsevier; 1984:13-16

14. R Maini, J O Sullivan, A Reddy, S Watson, $\mathrm{C}$ Edelsten, The risk of complications of 
uveitis in a district hospital cohort, $\mathrm{Br} \mathrm{J}$ Ophthalmol. 2004,88,512-17

15. Richard A Zorab, Intraocular Inflammation and Uveitis, American Academy of Ophthalmology. 2010-2011

16. Shrestha J B, Shah D N. Systematic association of uveitis in Nepalese population. Journal of Chitwan Medical college. 2017;7(19):35-40

17. Manandhar A. Pattern of Uveitis and Scleritis in Nepal. A Tertiary Referral Center study.Ocul Immunol Inflamm. 2017;25(sup1):S54-S62.

18. Rathinam SR, Namperumalsamy $P$. Global variation and pattern changes in epidemiology of uveitis. Indian $\mathrm{J}$ Ophthalmol. 2007;55:173-83

19. Ozdal MP, Yazici A, Tufek M, Ozturk F. Epidemiology of uveitis in a referral hospital in Turkey. Turk J Med Sci. 2014;44:337-42

20. Ebrahim M. Nashtaei1,Masoud Soheilian1, Carl P. Herbort,Mehdi Yaseri1. Patterns of Uveitis in the Middle East and Europe. J Ophthalmic Vis Res. 2011; 6 (4): 233-40.

21. Ralph D Levinson. Uveitis, Anterior, Nongranulomatous Treatment and Management Medscape, Nov 15, 2012

22. Albert and Jakoiec: Principles and practice of Ophthalmology; Second Edition; 2000;1225-1234

23. Quan Dong Nguyen. A cross sectional study of the Current Treatment Patterns in Noninfectious uveitis among Specialists in the US, American Academy of Ophthalmology, Volume 118, issue 1, Jan 2011, 184-190

24. Ralph D Levinson et al, Uveitis, Anterior, Nongranulomatous Treatment and Management Medscape, Nov 15, 2012

25. Mayo Foundation for Medical Education and Research, Uveitis, June 9, 2011

26. Jennifer E, Juvenile Idiopathic ArthritisAssociated Uveitis:Incidence of Ocular Complications and Visual Acuity Loss. Am J Ophthalmol. 2007;143:840-846

27. Victor Meneze and Susan Lightman, The development of complications in patient with chronic anterior uveitis, vol 139, issue 6, June2005, 988-992 